\title{
A PORTABL CHEMICAL INJECTION UNIT FOR IRRIGATION SYSTEMS
}

\author{
A. M. El Lithy ${ }^{(*)}$
}

\begin{abstract}
The principal aim of this research is to study the affecting factors the design of a portable chemical (fertilizers, pesticides, and anti-clogging agents) injection unit (CIU) powered with engine, and evaluate the designed (CIU) with pressurized irrigation system, for easy operation and maintenance of chemigation application to cover growers/irrigation designers needs for efficient (CIU) with independent power supply, using an economical materials available in the local market, and to add the designed (CIU) as a choice in expert system program help in proper selection of (CIU) according to field conditions, and to overcome field chemigation problems in pressurized irrigation system at many farms such as; unavailable power source, limited irrigation quantity and time period, long or large main line distance/size and improper field location to water source and irrigation pump. In addition, the designed chemigation injection unit (CIU) is compared with other fertilizer injectors available in the local market.

The main results in this study can be summarized in the following:

* Average injection rate ranged from 0.1 to $0.25 \mathrm{~m}^{3} / \mathrm{h}$, for imported injectors, and 0.1 to $1.2 \mathrm{~m}^{3} / \mathrm{h}$ for developed CIU. Injection pressure ranged from 2 to 4 bar. (200 - $400 \mathrm{kPa}$ ) and from 0.5 to 4 bar. (50 $400 \mathrm{kPa}$ ) for imported injector and developed $C I U$ respectively.

* The average uniformity of injection rate was $99 \%$ during chemigation time for developed injection unit .

* Economical verification of the feasibility of using the developed and imported injectors is discussed.
\end{abstract}

\section{INTRODUCTION}

ertigation is an effective method of applying chemicals and
fertilizers to crops via the existing irrigation system. It increases
efficient use of water and fertilizers, produces higher yields,

(*) Assoc. Prof., Ag. Eng. Dept., Col. of Ag., Al -Azhar U., Assiut. 
improvises quality of the production and protects environment. To ensure uniform distribution of water and fertilizers, the irrigation system must be properly designed. The choice of suitable fertilizers is also very important and based on several factors like nutrient form, purity, solubility, and cost.

Janos (1995) stated that to inject the fertilizer solution into the irrigation system four different fertigators can be used: Venturi, by-pass flow tank, pressure differential system or injection pump. The general advantages of the injection pump system are: the high degree of control of dosage and timing of chemical application, centralized and sophisticated control, portability, no serious head loss in the system, labor-saving and relatively cheap in operation. With this method the solution is normally pumped from an open unpressurized tank, and the choice of type of pump used is dependent on the power source. The pump may be driven by water flow, by an internal combustion engine, by an electric motor or by a tractor power take-off.

Kranz et al. (1996) found that chemical injection devices (piston, diaphragm, and venturi type injection) with the same model number do not deliver identical calibration curves, outlet pressure significantly affects the slope of the calibration curve, and the manufacturer calibration curve may not be appropriate for the operating conditions experienced with most center pivot installations, for a series of outlet pressures ranging from 207 to $690 \mathrm{kPa}$ (30 to $100 \mathrm{psi}$ ).

Coates et al. (2012) reported that all fertigation techniques performed well, with fertilizer distribution uniformities between 0.88 and 0.96 . Selection of the optimum site-specific fertigation strategy will depend on crop needs, scheduling limitations, and system design parameters such as emitter type, fluid travel time, and slope.

Jiusheng et al. (2007) stated that both manufacturing variability of emitters and injector types had a very significant effect on the uniformity of fertilizer applied, while the uniformity of water application was mainly dependent on emitter type.

Using of positive displacement pump for fertilizer injection with drip irrigation system decrease emitter clogging compared with by pass pressure mixing tank and venturi injectors. El Gendy et al. (2009).

Misr J. Ag. Eng., July 2012 
On the middle of 90s some of the farmers inject the fertilizer through the irrigation system by the suction pipe of the irrigation water pumps. Nowadays in Jordan $39.4 \%$ of the farmers are used this method to the fertilizer through the irrigation system. EL Zuraiqi. et al. (2004).

Bakeer (2002 a and b) and. Badr et al. (2006), recommended avoiding fertigation devices that depend on the differential pressure between the inlet and outlet as much as possible and using hydraulically actuated chemigator for saving water, energy and money.

Kassem and AL-Suker (2009) reported that fertigation using injection pump records efficient and highest values of water and nitrogen use efficiency for wheat and barley crops, among different methods of fertilizer application used, according to the experimental results during 2006/2007 and 2007/2008 seasons in experimental farm conditions of AlQassim University.

It is important to develop a portable chemical injection unit for irrigation systems, to cover growers/irrigation designers needs for efficient (CIU) with independent power supply, using an economical materials available in the local market in order to overcome field chemigation problems in pressurized irrigation system at many farms such as; unavailable power source, limited irrigation quantity and time period, long or large main line distance/size and improper field location to water source and irrigation pump. The aims of this research are:

1. Study the affecting factors on design of a portable chemical injection unit (CIU).

2. Test available materials to develop (CIU),

3. Evaluate the designed (CIU) in irrigation system,

4. Conduct field experiments to identify optimum design parameters and most appropriate materials, and

5. Compare the designed (CIU) with other chemical injectors available in the local market.

\section{MATERIALS AND METHODS}

Field experiments: Field experiments were conducted from 2009 to 2012 seasons to test the durability and designed parameters of developed chemical injector unit (CIU) including: 
(a) Testing developed (CIU) and other imported injector types (available in the local market) with irrigation system,

(b) Identifying technical, hydraulic and engineering characteristic for developed and imported injectors for comparison and optimization, and

(c) Comparing the designed (CIU) with other injectors available in the local market.

\section{Components of the developed chemical injection unit (CIU).}

The developed portable chemical injection unit (CIU) can be used for localized chemical injection with irrigation system, to control overwatering crop. It has the advantage that overcomes unavailability of power source, and chemigation problems in irrigation systems, by using an efficient, accurate, and durable positive displacement injection-pump powered with a small petrol engine (independent power-supply) to inject an agricultural chemicals at a constant rate in proper time regardless of flow or pressure changes in the system. The developed portable chemical injection unit (CIU) consists of three main-parts (from available materials in the local market), as shown in figs. 1 as follows.

(1) Chassis: The chemical injection unit chassis was designed and fabricated from steel beams consisting of four U-shape beams with dimensions of "900 x 50 x $100 \mathrm{~mm}$ " and "500 x 50 x $100 \mathrm{~mm}$ " for each two beams and three L-shape beams with dimensions of " $400 \times 50 \times 4$ $\mathrm{mm}$ " assembled by welding and fitted for engine and injection-pump installation using bolts and nuts.

(2) Engine: The petrol (gasoline) engine with air cooled has the following specs: Net-power output $3.6 \mathrm{~kW}(4.8 \mathrm{HP})$ at $3600 \mathrm{rpm}$, maximum torque of 10.3 N.m generated at $2500 \mathrm{rpm}$ of counterclockwise PTO shaft rotation, The engine dimensions of "L x W x H" 305 x 341 x $318 \mathrm{~mm}$. The engine has fuel tank capacity of 3.6 liter, dry mass of $13 \mathrm{~kg}$. The engine was equipped with two V-belt and pulleys to transmit the power required at the proper speed for the injection pump.

(3) Injection pump: The injection pump dimensions are $400 \times 285 \times 365$ mm (length, width, height) made of a heavy duty industrial brass with gross dry mass $19 \mathrm{~kg}$, included three stainless-steel pistons and aluminum 

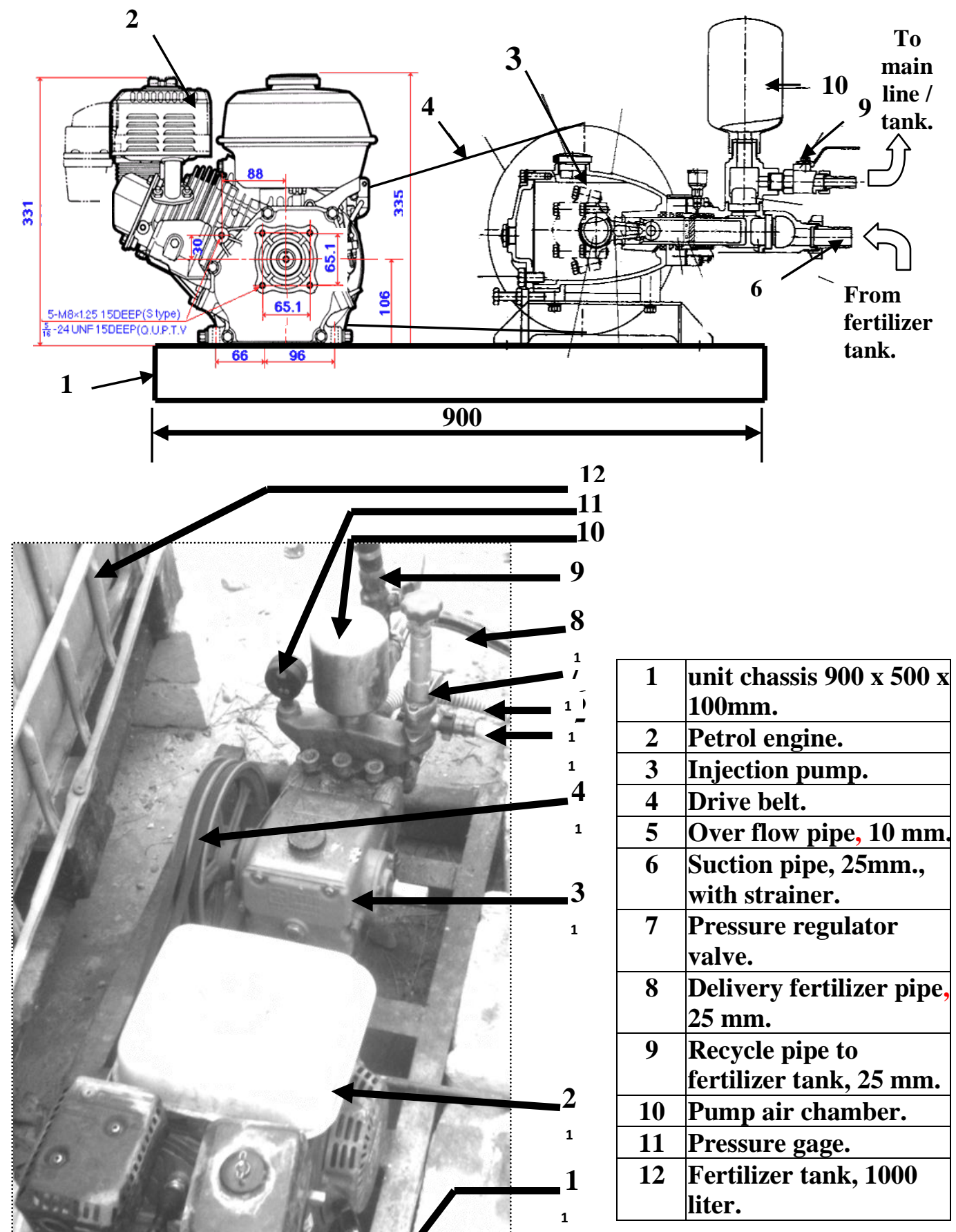

Fig. 1: Field installation and illustrative views of developed chemigation injection unit. 
pressure die casting connecting rod, equipped with control valve with pressure regulator, by-pass as a safety unit. In addition to air chamber to minimize output pressure pulse waves. All moving parts are lubricated by oil bath.

The designed (CIU) and two types of imported injectors (as shown in fig. 2) were tested according to International Standard for Agricultural Engineering equipment-water driven chemical injector pumps, BS ISO 13457:2008, to identifying technical characteristics and test the mechanical function such as : identify range of working pressure, injection rate and drive water-ratio.

\section{Chemical injection-rate:}

The injection rate of chemical was measured by recording chemical decreasing level in chemical tank with time using measuring tape with accuracy of $1 \mathrm{~mm}$.

Working pressure: A pressure gage range from 0 - 6 bar $(0-600 \mathrm{kPa})$ with an accuracy of 0.1 bar $(10 \mathrm{kPa})$ was used to measure working pressure.

Injector speed: The peed of the injector and the engine is measured by rpm meter directly.

\section{Chemical injection-unit power requirement:}

The power consumed can be estimated by measuring fuel consumption (by record volume required to refill the decrease in fuel level in the fuel tank immediately after each test) and using the following equation as used by El Nakib et al. (2011):

$$
F P=(F c / 3600) \rho_{\mathrm{f}} \times L € V \times \eta_{\text {th }} \times \eta_{\mathrm{m}}
$$

Where:

FP : Machine power, $\mathrm{kW}$,

Fc : Fuel consumption rate, $\mathrm{L} / \mathrm{h}$,

$\rho_{\mathrm{f}}:$ Density of fuel , $\mathrm{kg} / \mathrm{L}(0.73 \mathrm{~kg} / \mathrm{L}$, for gasoline $)$,

L€V: Lower calorific value of fuel, $\mathrm{kJ} / \mathrm{kg}$ (42000),

$\eta_{\text {th }}:$ Thermal efficiency of the engine (considered $25 \%$ for petrol engine), and

$\eta_{\mathbf{m}}$ : The mechanical efficiency of the engine (considered $80 \%$ for petrol engine). 


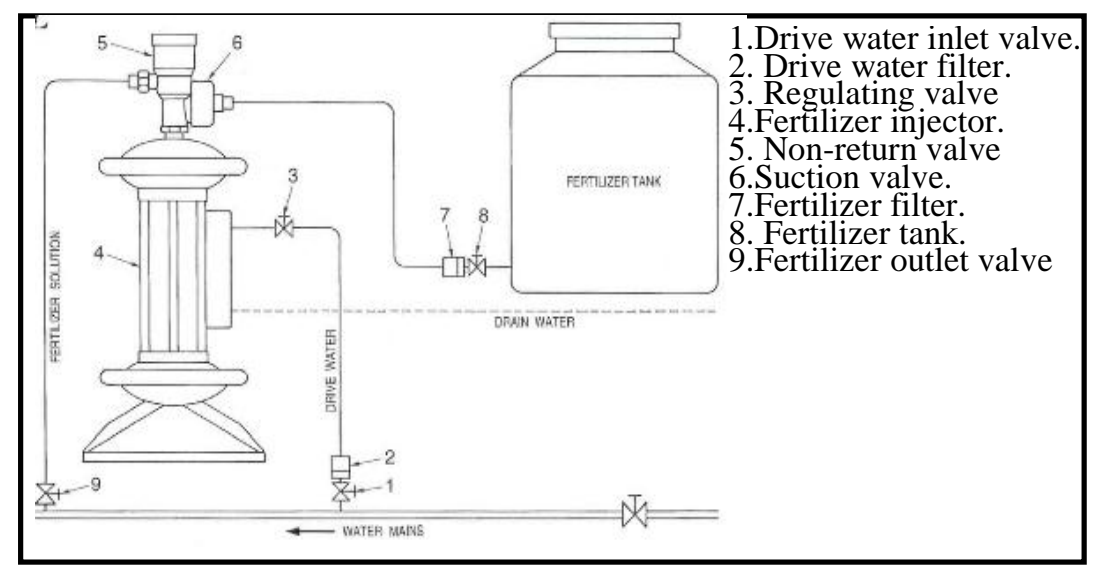

(a) Diaphragm drive injection-pump (I).

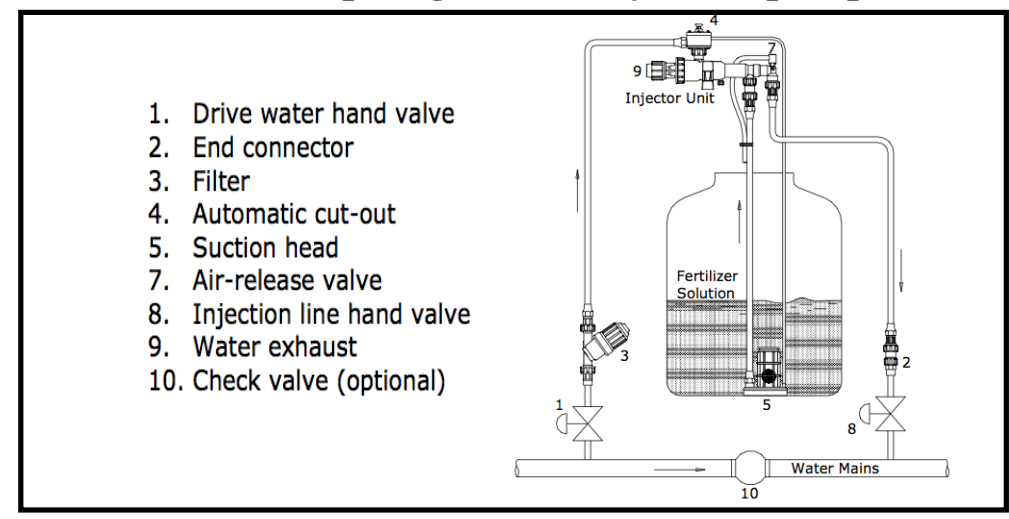

(b) Piston drive injection-pump (II).

Fig. 2: Typical installation diagrams (a \& b) of imported hydraulic chemical-injector types (diaphragm and piston).

Specific-power consumption.

Specific power consumption was calculated according to the following equation:

$$
\mathrm{SPC}=\mathbf{P} / \mathbf{q}
$$

\section{Where:}

SPC : Specific power consumption, $\mathrm{kW} . \mathrm{h} / \mathrm{m}^{3}$,

P : Mechanical or hydraulic power-consumed, $\mathrm{kW}$,

q : Injected chemicals, $\mathrm{m}^{3} / \mathrm{h}$. 


\section{Injection uniformity.}

The uniformity of injection rate was determined using Cheristiansen coefficient "CU" (Christiansen , 1942):

$$
\mathbf{C U}=(1-|\sigma|) .100
$$

where :

CU: Coefficient of uniformity

$|\sigma|$ : Absolute mean deviation of injection rate on injection time.

\section{Cost analysis}

The hourly cost for operating the developed and imported injector types was estimated using the following formulas (Awady, 1978):

$$
\begin{aligned}
& \mathrm{C}=(\mathrm{P} / \mathrm{h})((1 / \mathrm{e})+(\mathrm{i} / \mathbf{2})+\mathrm{t}+\mathrm{r}))+(1.2 \mathrm{w} \times \mathbf{f} \times \mathrm{s})+\mathrm{b} \\
& \mathrm{C}=(\mathrm{P} / \mathrm{h})((\mathbf{1} / \mathrm{e})+(\mathrm{i} / \mathbf{2})+\mathrm{t}+\mathrm{r}))+((\mathrm{w} \times \mathrm{s})+\mathrm{z})+\mathrm{b} \ldots
\end{aligned}
$$

Where:

C- Hourly cost, L.E/h,

p- Capital investment (injector-unit price),

h- Yearly operating hours (144 h.) (According to actual field conditions)

e- Life expectancy (10 years),

i- Interest rate/year. (10\%),

t- Taxes and over heads ratio (3\%),

r- Repairs and maintenance ratio (18\%),

f- Specific fuel consumption, $(0.85 \mathrm{~L} / \mathrm{kW} . \mathrm{h})$,

s- Price of fuel per liter: (1.75 L.E./L).and price of electric-energy $(0.25$ L.E /kW.h),

w- Engine power: $(3.6 \mathrm{~kW})$. or consumed hydraulic-power required (Power $(\mathrm{kW})=(($ Pressure head $(\mathrm{m}) \mathrm{x}$ inject rate including water consumed $\left.\left.\left.\left(\mathrm{m}^{3} / \mathrm{h}\right)\right) / 270\right) * 0.75\right)$ ) inject $0.25 \mathrm{~m}^{3} / \mathrm{h}$ (maximum injectrate) for imported injectors type),

z- Consumed water (exhausted price required for imported injectors works (0.2 L.E. $/ \mathrm{m}^{3}$ according to Bakeer (2002 a) and

b- Hourly labor-wage L.E./h. (6 LE/h).(as 2012 wage price.).

Injection cost chemicals. The following equation used to estimate cost of injected chemicals using different injector types.

$$
I_{c}=(1 / \text { injector rate }) \times \mathrm{V} \times \mathrm{C} \text {. }
$$

where: 
$\mathrm{I}_{\mathrm{c}}:$ Injection cost L.E. $/ \mathrm{m}^{3}$.

$\mathrm{V}$ : Required injected-volume, $\mathrm{m}^{3}$.

C: Hourly cost, L.E/h. of injectors from eq. 3 or 4 for developed or imported injectors.

\section{Correlation between measured and calculated data.}

The following equation used to calculate correlation between measured and calculated data. (Nigm, 1993):

$$
\mathrm{R}^{2}=\frac{\sum(x-\bar{x})(y-\bar{y})}{n \cdot \sigma_{x} \cdot \sigma_{y}}
$$

Where: $\mathrm{R}^{2}=$ correlation between two groups of data, $\mathrm{x}=$ data number in the first group, $\mathrm{x}, \mathrm{y}=$ average, $\mathrm{y}=$ data number in the second group $\sigma \mathrm{x}, \sigma \mathrm{y}=$ standard deviation, and $\mathrm{n}=$ number of data.

\section{RESULTS AND DISCUSSION \\ Hydraulic characteristics of designed chemical injection-unit (CIU).}

Fig. 3 shows the relation between injection rate and pressure at different injector speeds for designed chemical injection unit. It is clear that the designed unit has a wide range of operating pressures and injected rates, so that it is easy to notice that, about $79 \%$ increase in the average chemical injection rate occurred by, increasing of injector speed from 240 to 864 revolutions per minute (rpm). That give the operator more flexibility to chose, an optimum injection rate at proper injector speed for a wide rang of field operating conditions. Also it is clear that a slight decreasing about) $0.05 \%$ ) in injection rate at all injector speeds by increasing of pressure from 0 to $300 \mathrm{kPa}$. due to the injector pump efficiency.

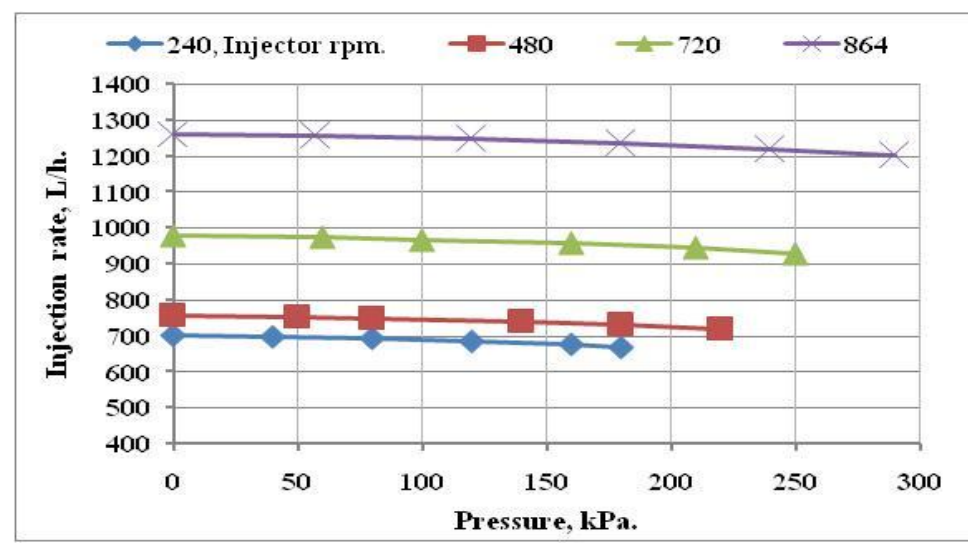

Fig. 3 : Developed injector unit characteristic at different injector speeds. 


\section{Injection-rate uniformity during injection time.}

It is clear from fig. 4 that injector speed has a small significant effect on injection uniformity for developed injector unit. The injection rate uniformity decreased from 99.2 to $98.6 \%$ by increasing injector speed from 240 to $864 \mathrm{rpm}$ for average injection rate 667 and $1200 \mathrm{~L} / \mathrm{h}$ respectively. The highest value of injection rate uniformity was recorded at the lowest injector speed due to the maximum volumetric efficiency of the injector with minimum injector speed.

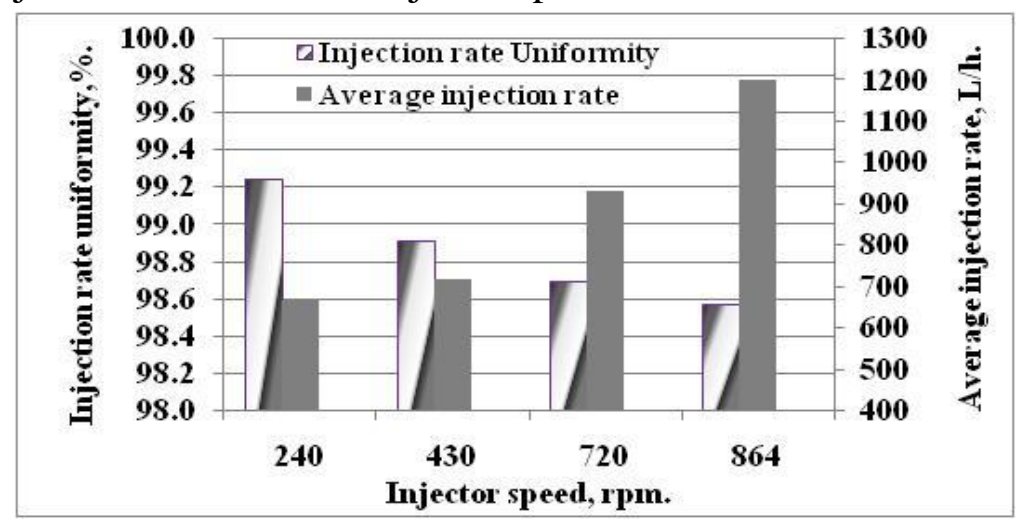

Fig. 4: Effect of injector speed on injection-rate uniformity and average injection-rate for designed chemical injection-unit.

\section{Injection rate during injection time.}

Fig. 5 reflects the effect of operating time on injector rate for developed chemical injection unit. The average of injection rate increased from 667 to $1200 \mathrm{~L} / \mathrm{h}$ by increasing injector speed from 240 to $864 \mathrm{rpm}$ during injection time.

Effect of injector speed on fuel consumption, injection rate and pressure for developed (CIU).

As result of increasing injector speed from 240 to $864 \mathrm{rpm}$, the percentage of fuel consumption, injector rate and pressure increased by $115.4,80$ and $115.4 \%$ for developed chemical injection unit as shown in fig. 6 .

Hydraulic characteristics of designed and imported types of chemical injectors.

Fig. 7 shows the relation between injection capacity and pressure of imported and designed chemical injection unites ( CIU ). It is clear that 


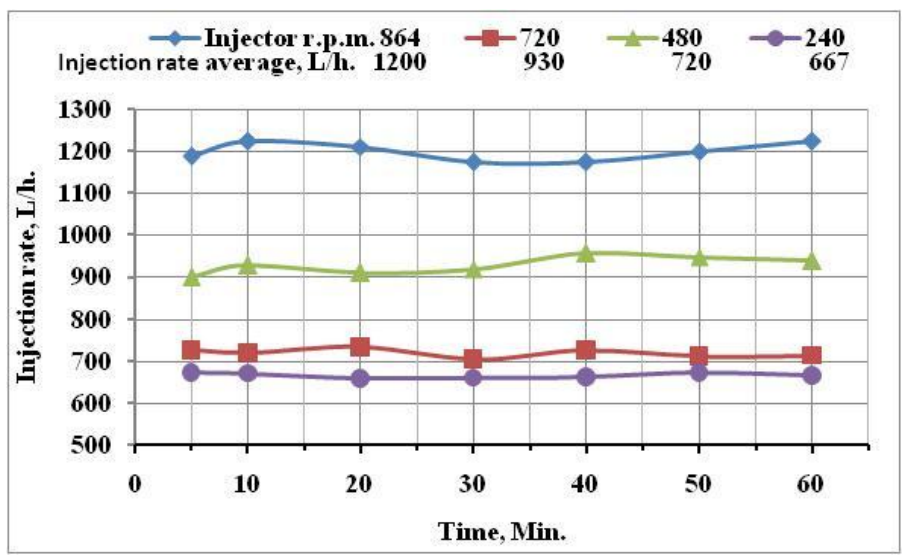

Fig. 5: Effect of injection time on injection rate at different injector speeds.

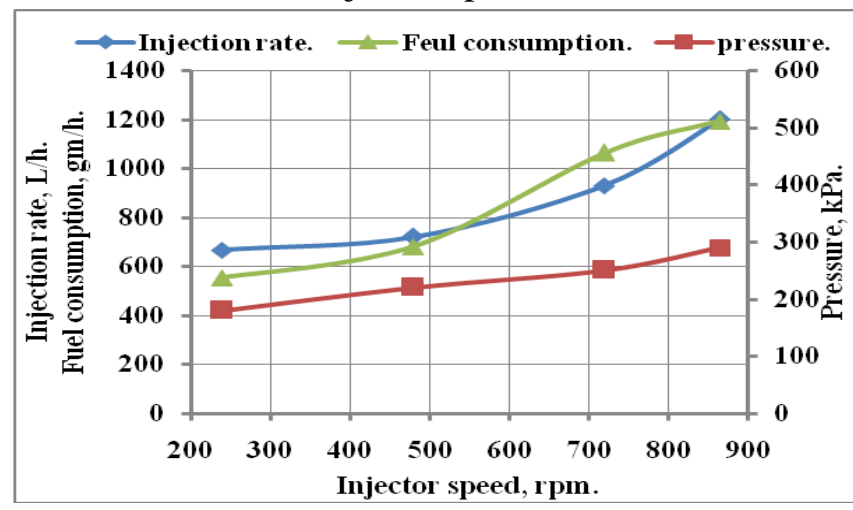

Fig. 6: Effect of injector speed on injection pressure, rate and fuel consumption.

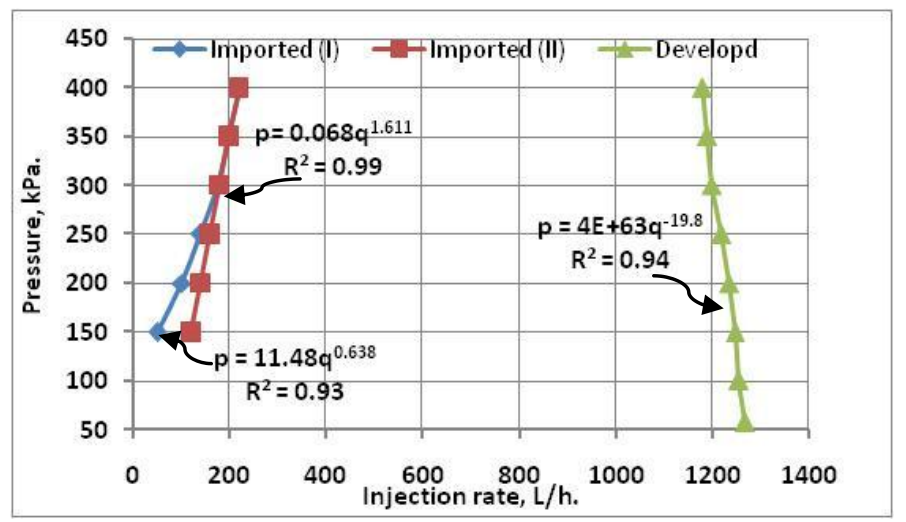

Fig. 7: Hydraulic characteristics of imported (two types) and developed chemical injectors. 
about $380 \%$ increase occurred in allowable average injection rate of designed (CIU) compared with imported types. In addition to the advantage of chemical injection regardless irrigation system characteristics.

The relation between pressure and injection rate for imported and designed (CIU) is expressed in three equations, shown in fig. 7 for each injector with acceptable correlation between measured and calculated data (93-99\%).

\section{Cost comparison.}

Tables 1 and 2 show that the total initial cost required for designed (CIU) and imported injectors types (I and II) were 3150, 3600, and 5400 L.E. respectively.

As a result of using developed chemical injector unit in pressurized irrigation systems, a saving of $42 \%$ and $13.5 \%$ was obtained in initial cost, also a saving of 81 and $79 \%$ was obtained per each cubic meter of chemical ejected in irrigation system, compared with using imported injector types (I and II).

Table 1: Cost details and comparison between designed and imported chemical-injectors.

\begin{tabular}{|l|c|c|c|}
\hline \multirow{2}{*}{$*$ Material } & \multicolumn{3}{|c|}{ Cost, L.E.* } \\
\cline { 2 - 4 } & \multirow{2}{*}{ Designed } & \multicolumn{2}{|c|}{ Imported } \\
\cline { 2 - 4 } & & Piston & Diaphragm \\
\hline Injector & 1000 & 3050 & 4850 \\
\hline Engine & 1600 & 0 & 0 \\
\hline Valves and filter & 150 & 300 & 300 \\
\hline Chassis & 150 & 0 & 0 \\
\hline Fertilizer tank & 250 & 250 & 250 \\
\hline Total & 3150 & 3600 & 5400 \\
\hline
\end{tabular}

*Material cost according to local market price, 2012. 
Table 2: The hydraulic and engineering characteristic with operating economics for details of the developed (CIU) and imported injectors.

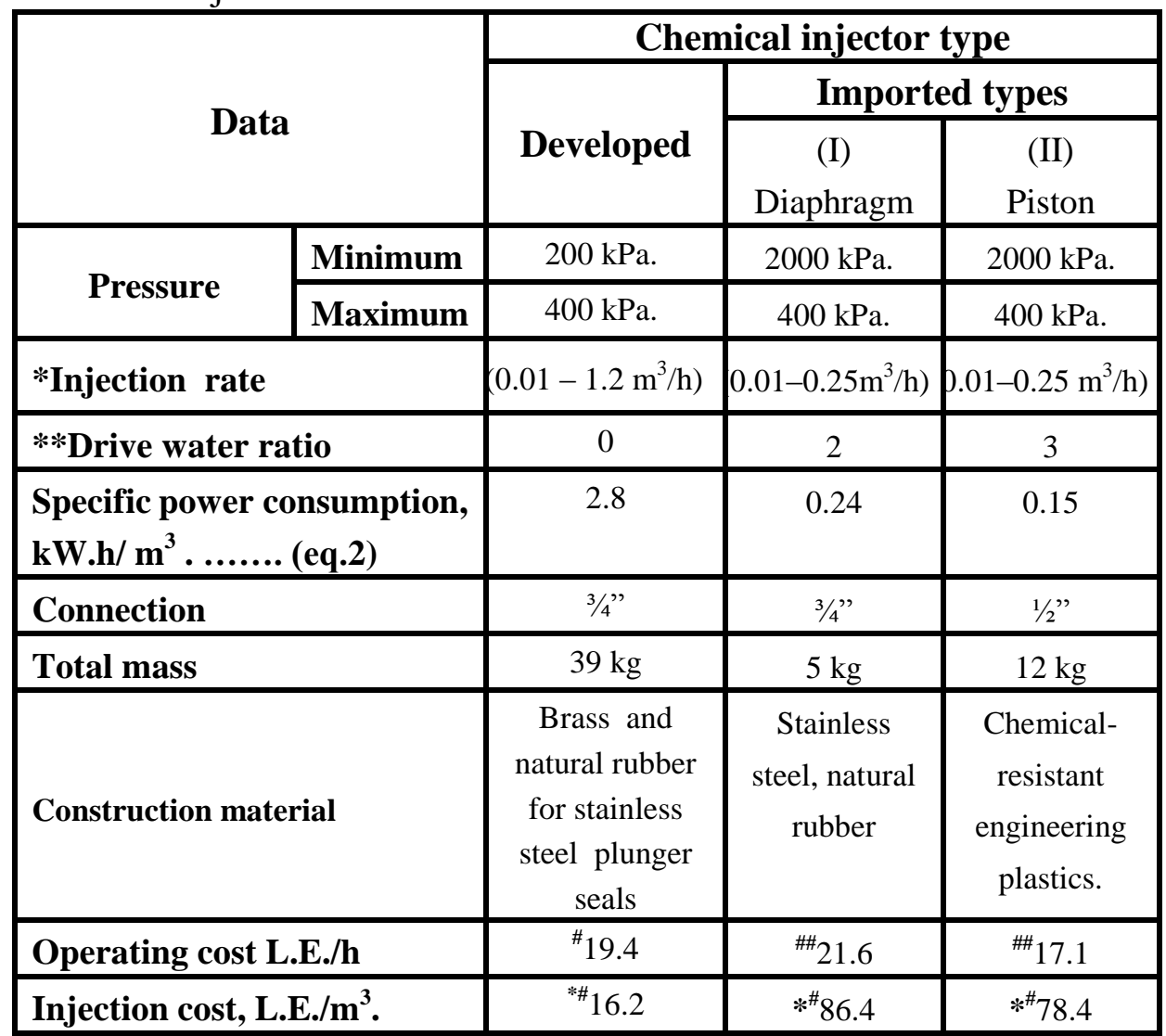

*Injection rate is related to the operating pressure of the irrigation pump for imported injector types.

** ratio of the volume of drive water to one unit volume of injected chemicals, (Cleaned water using filter mesh size, $(0.130 \mathrm{~mm}(130 \mu \mathrm{m}))$ required to inject the same unit volume of chemical solution. \# ,\#\# Estimated using eq. $1 \& 3$ and $1 \& 4$.

*\# ,\#\# Estimated using eq. 5

\section{SUMMARY AND CONCLUSION}

A new chemical injection unit (CIU) was designed and tested with irrigation system consisting of three main parts: (1) Chassis, (2) Petrol engine, (3) Injection pump.

The advantages of the developed chemical injector unit are:

(1) Innovated design for chemical injection in pressurized irrigation system with independent power source, (2) Simple design and manufacturing, (3) Fabricated from available materials, (4) Reliable and 
easy to install and maintain in the irrigation system and (5) High injection rate capacity with an economical cost compared with imported injectors. Three equations, derived from curve fitting of characteristics curve, can be used to get the injection pressure for injected flow rate with a acceptable correlation of $94 \%$, for designed unit(Eq. 6), and 93, 99\% for imported injector types (Eq. 7 and 8) (diaphragm and piston), respectively as following equations:

$$
\begin{gathered}
P=4 E+63 q^{-19.8} \\
P=0.068 q^{1.61}
\end{gathered}
$$

Where: "q" is the rate of injection, $\mathrm{L} / \mathrm{h}$, "P" injection pressure, $\mathrm{kPa}$. The average of injection rate was 1200 and $250 \mathrm{~L} / \mathrm{h}$ for designed and imported injector types ((I) diaphragm and (II) piston).

The total initial cost of designed and imported injectors (diaphragm(I),piston (II)) for irrigation systems was 3150 and 3600,5400 L.E. respectively.

The injection rate uniformity for the designed (CIU) ranged from 98.6 to $99.2 \%$ for injection rate 1200 and $667 \mathrm{~L} / \mathrm{h}$ at injector speeds 864 and 240 rpm respectively.

A savaging of 81 and $79 \%$ was obtained per each cubic meter of chemical ejected in irrigation system, by using developed injector compared with using imported injector types (I and II) respectively.

\section{REFERENCES}

Awady, M. N. ,1978, Tractor and farm machinery. Txt bk., Col. Ag., Ain Shams U.: 146-167.

Badr, A. A., Ebabi, F. G., and ELtomy, E. O., 2006, Fertigation methods effects on water and fertilizer uniformity in drip irrigation, Misr J. Ag. Eng., 23(1): 122 - 136.

Bakeer, G. A., 2002 a, Chemical injection effect on deep whell-pump in drip irrigation, Misr J. Ag. Eng., 19(4): 821- 840.

Bakeer, G. A., 2002 b, Fertigation methods effects onwater and fertilizer uniformity in drip irrigation, Misr J. Ag. Eng., 19(4): 821- 840.

Christiansen, J.E., 1942, Irrigation by Sprinkling. California Agriculture Experiment Station Bulletin, No. 670. 
Coates, R. W., Sahoo, P. K., Schwankl, L. J. and Delwiche, M. J., 2012, Fertigation techniques for use with multiple hydrazones in simultaneous operation. Precision 13(2): 219-235.

El Nakib, A. A., Rasmy, A. S., and Mahmoud, A. A., 2011, Evaluation of a pneumatic orchard tree pruning machine ( prototype), Misr J. Ag. Eng., 28(4): 91- 106.

EL Zuraiqi S., Rusan, M. J., and AL Qawasmi, W., 2004, Fertigation in Jordan, IPI Regional Workshop on Potassium and Fertigation development in West Asia and North Africa; Rabat, Morocco: 24-28.

El-Gindy, A. M, Tayel, M.Y. , El-Bagoury, K.F., and Sabreen, K. A., 2009, Effect of injector type and nitrogen treatment on emitters clogging, Misr J. Ag. Eng., 26(3): 1263- 1276

INTERNATIONAL STANDARD, 2008, BS ISO 13457, Agricultural irrigation equipment-Water-driven chemical injector pumps, 2 nd.: 122.

Janos, L., 1995, Application of chemicals through irrigation systems. ICID J. 45 No. 2: 125-146.

Jiusheng, L., Yibin, M., and Bei, L., 2007, Field evaluation of fertigation uniformity as affected by injector type and manufacturing variability of emitters, Ir. Sc., Volume 25 (2): 117-125.

Kassem, M. A., and AL-Suker, A., 2009, Effect of fertigation methods on productivity and nitrogen use efficiency for wheat and barly crops, Misr J. Ag. Eng., 26(2): 866- 885.

Kranz, W. L., Eisenhauer, D. E., Parkhurst, A. M., 1996, Calibration accuracy of chemical injection devices, Applied Engineering in Agriculture. 12(2): 189-196.

Negm, A. M., 1993, Descriptive and analytical statistics by using ready made software, P. 199.(In Arabic).

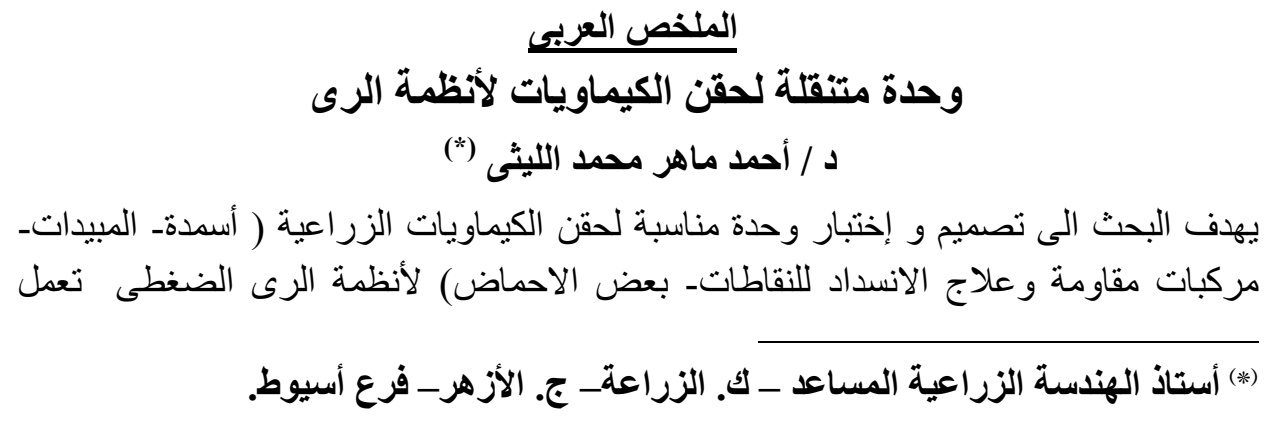


بمحرك بنزين ، مع سهولة التشغيل و الصيانة لوحدة حقن الكيماويات المصممة عمليا لبساطة

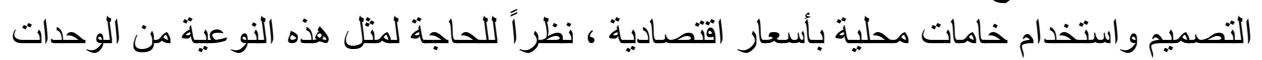

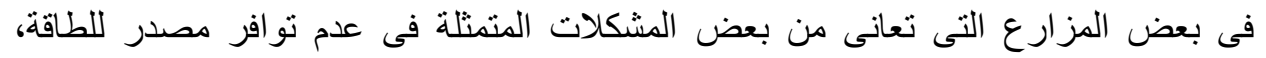

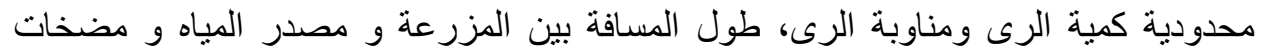

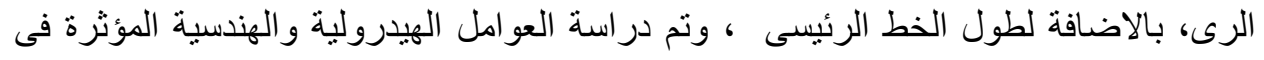

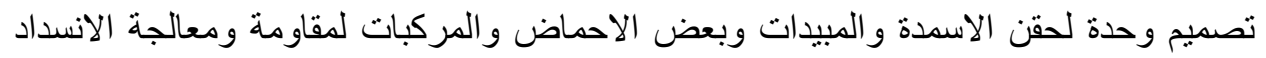

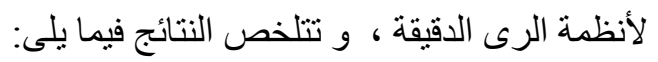

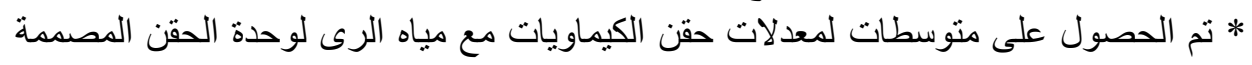

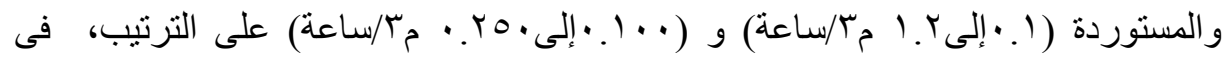

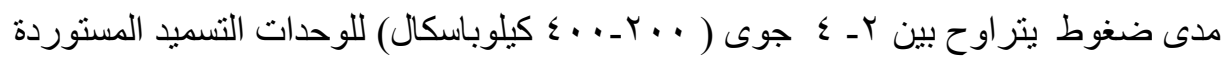

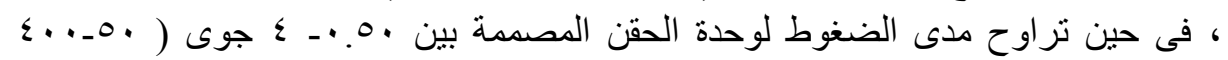

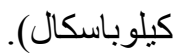

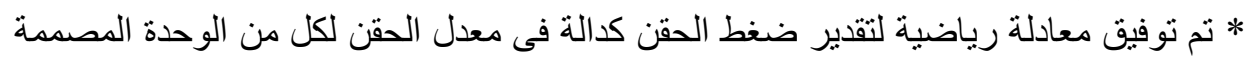

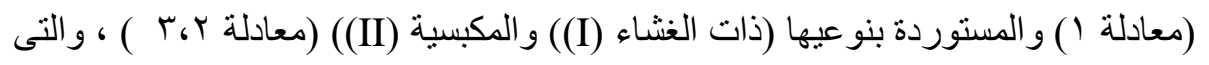

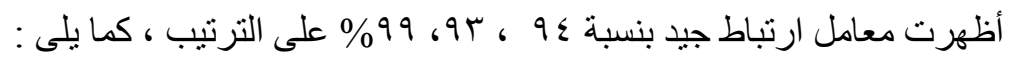

$$
\begin{array}{r}
P=4 E+63 q^{-19.8}-(1) \quad P=11.480 q^{0.638} \\
P=0.068 q^{1.61} \text {.-...- (3) }
\end{array}
$$

حيث: " P " تمثل ضغط الحقن بوحدات كيلو باسكال (kPa) بينما، "qu " تمثل معدل الحقن

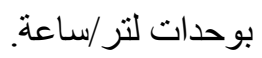

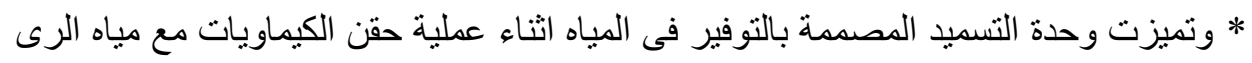

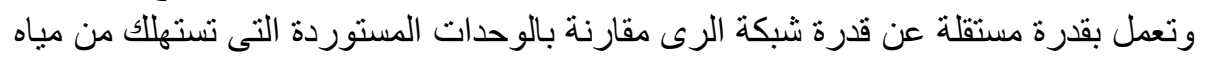

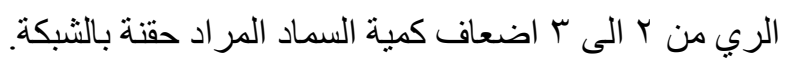

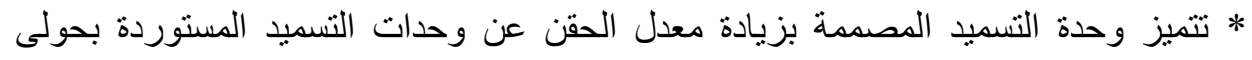

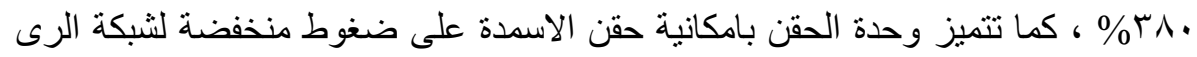

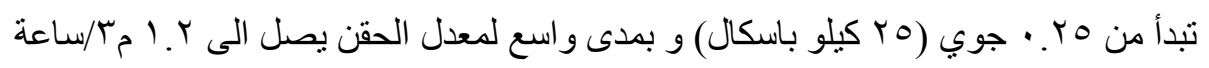

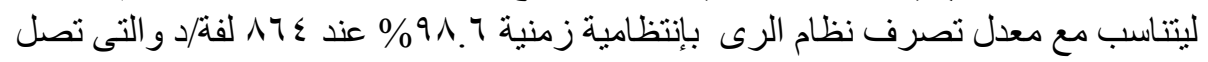

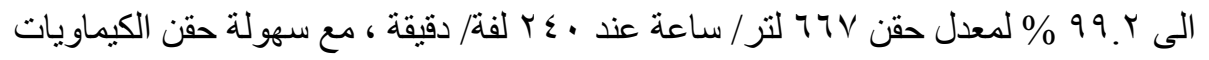

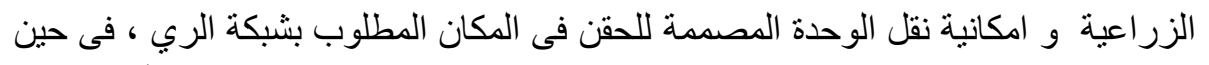

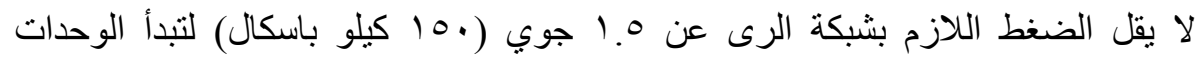

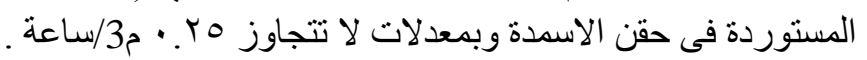

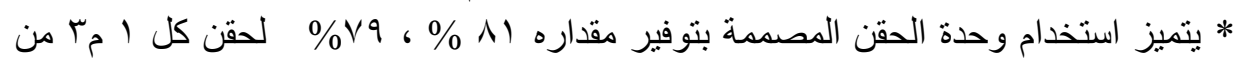

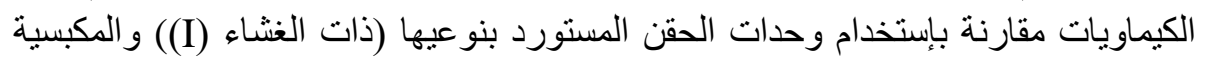

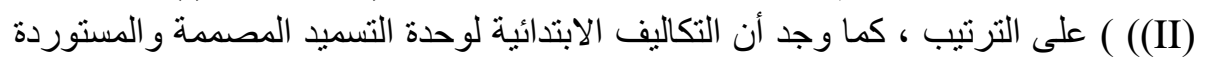

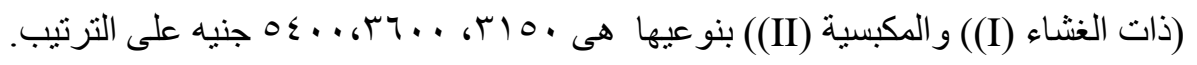

